\title{
Morphometric studies of small follicles in ovaries of women at different ages
}

\author{
A. Gougeon and G. B. N. Chainy* \\ Physiologie et psychologie de la reproduction humaine, INSERM U187, 32 rue des Carnets, \\ 92140 Clamart, France
}

\begin{abstract}
Summary. Small follicles in human ovaries were divided into 4 groups based on the morphological characteristics of the granulosa cells that surround the oocyte: $B$ (flattened cells), B/C (mixture of flattened and cuboidal cells), $\mathrm{C}$ (one layer of cuboidal cells) and D (more than one layer of cells without epithelioid cells in the theca interna). On the basis of morphometric studies, including the number of granulosa cells in the largest cross-section, diameters of follicle, oocyte and germinal vesicle, folliculogenesis was categorized as in a dormant or growth phase. During the dormant phase, a transformation of follicles from Type B to Type C progressively took place. The growth phase started at an intermediary stage between large Type $\mathrm{C}$ and $\mathrm{D}$ follicles. The total ovarian follicular population and the numbers of each follicle type decreased significantly as age increased. The percentages of Type B follicles significantly decreased with increasing age whereas the percentages of Types $\mathrm{B} / \mathrm{C}, \mathrm{C}$ and $\mathrm{D}$ increased. In addition, there was a positive correlation between the percentages of Type $B$ and a negative correlation between the percentages of Types $B / C, C$ and $D$ and the total ovarian follicular population. This last observation suggests the existence of an intra-ovarian regulation of the first steps of follicular growth.
\end{abstract}

\section{Introduction}

The small follicles constitute the largest part of the ovarian follicular population and despite the works of Block (1951a, b) and Lintern-Moore et al. (1974) little is known about the kinetics of the first steps of follicular growth in the human ovary. The pool size of small follicles appears to be the determining factor in regulating the number of follicles leaving the pool (mouse: Krarup et al., 1969 ) or in the growing phase (human: Gougeon, 1984). This process has been shown to be independent of gonadotrophins by Peters et al. (1973b).

The present investigation was undertaken to study in detail the morphometric characteristics of the population of small follicles and its change with age in women.

\section{Materials and Methods}

Sampling and processing. Whole ovaries (80) and large ovarian resections (6) were obtained from 49 subjects undergoing surgery for various gynaecological disorders not directly related to pathological conditions of the ovary (ovariectomy for carcinoma of the breasts or cervix, hysterectomy for fibroids). The patients were aged 19 to 49 years (mean \pm s.d. $=41.4 \pm 6.7$ years)

Ovarian function was considered to be normal after verification of the following criteria: (i) absence of morphological pathology of the ovary, (ii) regular menstrual cycles $(28 \pm 3$ days) determined over the 3 previous

\footnotetext{
*Present address: Department of Zoology, Utkal University, Bhubaneswar, 751004 India.
} 

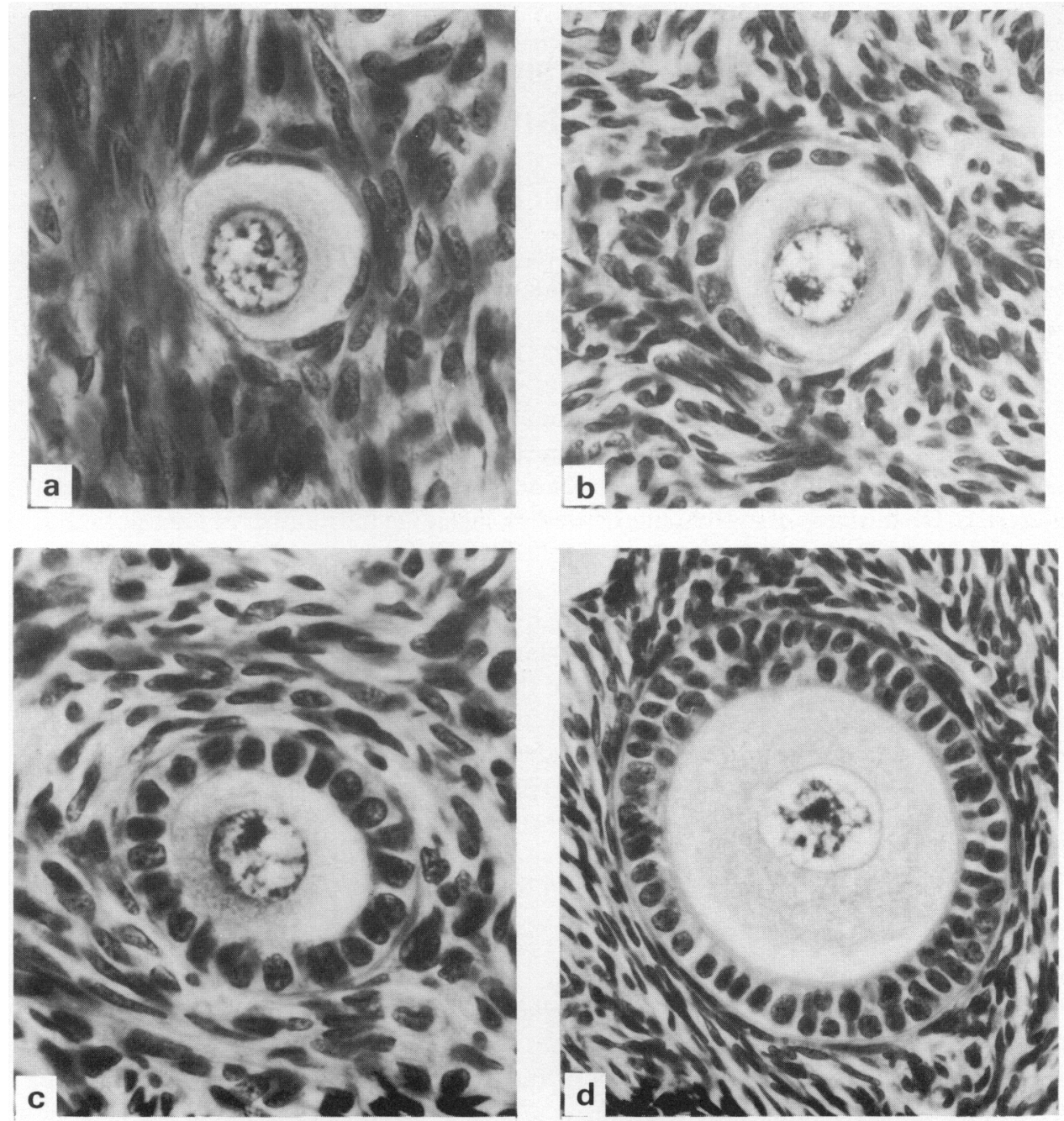

Fig. 1. Illustrations of follicle types: (a) Type B, $\times 570$; (b) Type B/C, $\times 570$; (c) Type $C, \times 570$; (d) Type D, $\times 410$.

cycles, (iii) occurrence of ovulation in each of the 3 previous cycles, confirmed by the presence of corpora lutea at various stages of degeneration (Gougeon \& Lefèvre, 1984), and (iv) no recent hormonal treatment.

The samples were fixed in Bouin's fluid or alcohol-formaldehyde-acetic acid within $20 \mathrm{~min}$ after sampling; they were serially sectioned at $10 \mu \mathrm{m}$ and then stained with haematoxylin-Masson blue.

Classification of small follicles. The follicles have been classified into 4 groups as proposed by Lintern-Moore $e t$ al. (1974) for the infant human ovary: (i) Type B: follicles in which oocytes are surrounded by flattened granulosa cells (Fig. 1a); (ii) Type B/C: follicles in which oocytes are surrounded by a mixture of flattened and cuboidal granulosa cells (Fig. 1b); (iii) Type C: follicles in which oocytes are surrounded by a single layer of cuboidal granulosa cells (Fig. 1c); and (iv) Type D: follicles in which oocytes are surrounded by more than one layer of cuboidal granulosa cells but where epithelioid cells had not differentiated in the theca layer (Fig. 1d). The latter corresponds to the C/D and D classes of the classification of Lintern-Moore et al. (1974). These morphological characteristics seemed to us a better reflection of the functional development of the follicles than the follicular diameter as proposed by Koering (1983) for monkey.

Calculations. Follicle dimensions were measured with an ocular micrometer. The basement membrane of the follicle was taken as the outer limit of the follicle. Follicular diameter was taken at right angles in the section where the nucleolus of the oocyte was observed. The same process was used to estimate the diameters of the oocyte and its 
nucleus. The number of squamous and cuboidal granulosa cells surrounding the oocyte in the largest cross-section was corrected by the Floderus correction factor (Block, 1951a). These morphometric values were measured on 1000 follicles from 9 ovaries (5 patients) sampled at different times during the menstrual cycle.

The total number of follicles of each group was estimated for each ovary by using the following correction factor:

$$
\mathrm{N}_{\mathrm{t}}=\frac{\mathrm{N}_{o} \times \mathrm{S}_{\mathrm{t}} \times \mathrm{t}_{\mathrm{s}}}{\mathrm{S}_{\mathrm{o}} \times \mathrm{d}_{\mathrm{o}}}
$$

where $N_{t}=$ total calculated number of follicles of one type; $N_{o}=$ number of follicles observed in the ovary; $S_{t}=$ total number of sections in the ovary; $\mathrm{t}_{\mathrm{s}}=$ thickness of the section $(\mu \mathrm{m}) ; \mathrm{S}_{o}=$ total number of sections observed; and $\mathrm{d}_{\mathrm{o}}=$ mean diameter of the nucleus of that follicle type.

Statistical methods. The statistical significance of the observed differences was determined by Student's $t$ and paired $t$ tests as appropriate.

\section{Results}

\section{Distribution of small follicles on the basis of their diameter}

The distribution of follicles on the basis of their diameter was approximately the same in all the ovaries studied (Table 1). About $2 \%$ of the total follicular population showed a diameter of $<30.0 \mu \mathrm{m}$ and more than $87 \%$ had a diameter between 30.0 and $44.9 \mu \mathrm{m}$. The remaining $10 \%$ of the population were scattered within the range of $45 \cdot 0-110 \cdot 0 \mu \mathrm{m}$.

\section{Distribution of follicles of Types $B, B / C, C, D$ on the basis of their diameter}

The frequency distribution pattern of each type is shown in Fig. 2. The data suggest that follicles of Types B and B/C mostly had a diameter between 30.0 and $42.5 \mu \mathrm{m}$. For follicles of Types $\mathrm{C}$ and $\mathrm{D}$, the diameters were between 37.5 and $52.5 \mu \mathrm{m}$, and 50.0 and $90.0 \mu \mathrm{m}$ respectively.

\section{Follicular development}

In the whole population of small follicles the analysis of the relationships between three morphometric values, i.e. oocyte diameter, follicle diameter and granulosa cell number in the

Table 1. Frequency distribution of small follicles $(n=1000)$ according to their follicular diameter in 9 ovaries from 5 subjects

\begin{tabular}{|c|c|c|c|c|c|c|c|c|}
\hline \multicolumn{2}{|c|}{ Follicular diameter $(\mu \mathrm{m})$} & \multirow{2}{*}{$\begin{array}{l}\text { No. of } \\
\text { follicles }\end{array}$} & \multicolumn{5}{|c|}{$\begin{array}{l}\% \text { of ovarian follicular population } \\
\text { in individual patients }\end{array}$} & \multirow{2}{*}{$\begin{array}{l}\text { Mean } \pm \text { s.d. } \% \text { of } \\
\text { small follicular } \\
\text { population }\end{array}$} \\
\hline Range & Mean \pm s.d. & & A & B & $\mathrm{C}$ & D & $\mathbf{E}$ & \\
\hline$<30.0$ & $29 \cdot 1 \pm 1 \cdot 4$ & 21 & $3 \cdot 5$ & 0.5 & $2 \cdot 5$ & $2 \cdot 5$ & $2 \cdot 5$ & $2 \cdot 3 \pm 1 \cdot 1$ \\
\hline $30 \cdot 0-34 \cdot 9$ & $33.4 \pm 3.2$ & 250 & $23 \cdot 5$ & $23 \cdot 0$ & 29.5 & $28 \cdot 0$ & $20 \cdot 5$ & $24.9 \pm 3.8$ \\
\hline $35 \cdot 0-39 \cdot 9$ & $37 \cdot 3 \pm 4 \cdot 0$ & 410 & $42 \cdot 5$ & $43 \cdot 5$ & $36 \cdot 0$ & $42 \cdot 0$ & $38 \cdot 0$ & $40 \cdot 4 \pm 3 \cdot 1$ \\
\hline $40 \cdot 0-44 \cdot 9$ & $41.8 \pm 2.9$ & 213 & $16 \cdot 5$ & $27 \cdot 5$ & $20 \cdot 5$ & $17 \cdot 5$ & $30 \cdot 5$ & $22 \cdot 5 \pm 6 \cdot 3$ \\
\hline $\begin{array}{llll}45 \cdot 0 & 49 \cdot 9\end{array}$ & $47 \cdot 1 \pm 1 \cdot 3$ & 40 & $4 \cdot 0$ & 4.0 & $5 \cdot 0$ & $4 \cdot 5$ & $4 \cdot 5$ & $4.4 \pm 0.4$ \\
\hline $50 \cdot 0-54 \cdot 9$ & $51.8 \pm 1.3$ & 18 & $1 \cdot 5$ & 0.0 & 1.5 & $2 \cdot 5$ & 1.5 & $1.4 \pm 0.9$ \\
\hline $55 \cdot 0-59 \cdot 9$ & $57.9 \pm 1.5$ & 15 & $3 \cdot 0$ & 1.0 & 0.5 & 0.5 & $1 \cdot 0$ & $1 \cdot 2 \pm 1 \cdot 1$ \\
\hline $60 \cdot 0-69 \cdot 9$ & $64 \cdot 4 \pm 2.4$ & 12 & $2 \cdot 0$ & 0.5 & $2 \cdot 5$ & 0.0 & $1 \cdot 0$ & $1 \cdot 2 \pm 1 \cdot 1$ \\
\hline $70 \cdot 0-79 \cdot 9$ & $74 \cdot 1 \pm 3 \cdot 2$ & 10 & $2 \cdot 0$ & 0.5 & 0.5 & 0.5 & 0.0 & $0.7 \pm 0.7$ \\
\hline$>80 \cdot 0^{*}$ & $91.7 \pm 13.6$ & 11 & 1.5 & 0.5 & 1.5 & $2 \cdot 0$ & $0 \cdot 0$ & $1 \cdot 1 \pm 0 \cdot 8$ \\
\hline
\end{tabular}

*Follicles without epithelioid cells in the theca interna. 


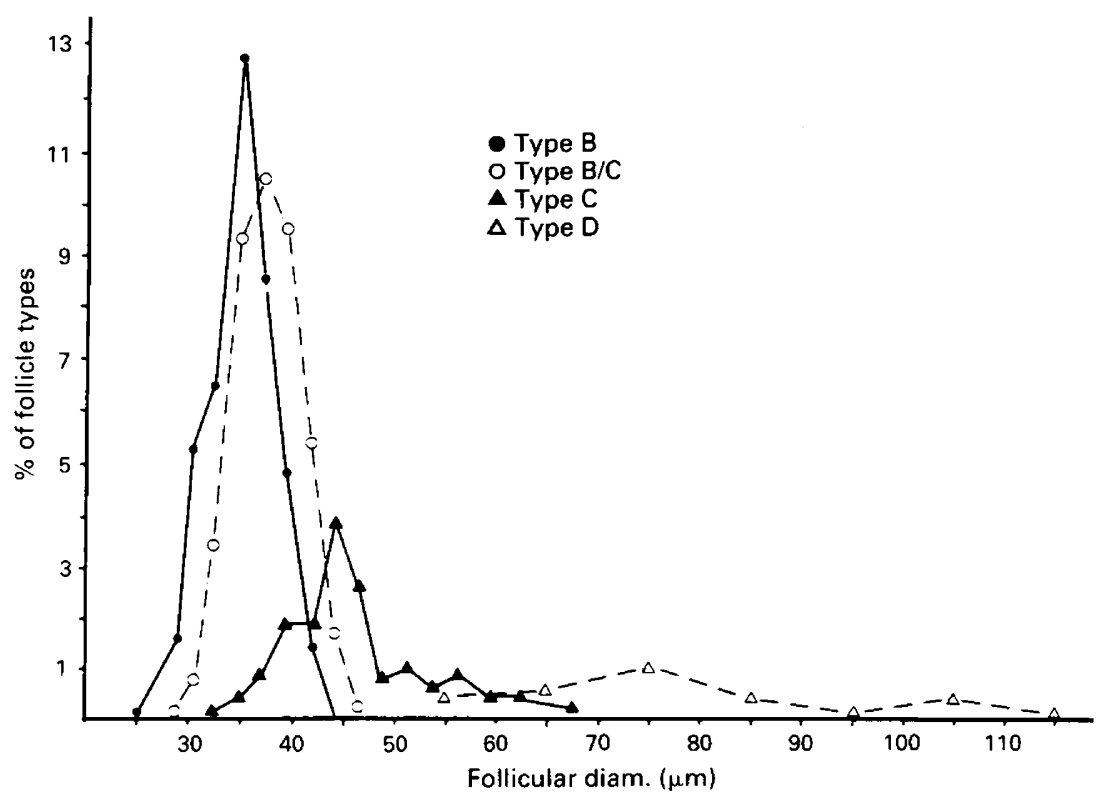

Fig. 2. Frequency distribution pattern of 1000 small ovarian follicles, from the ovaries of 5 patients, in relation to follicle diameter.
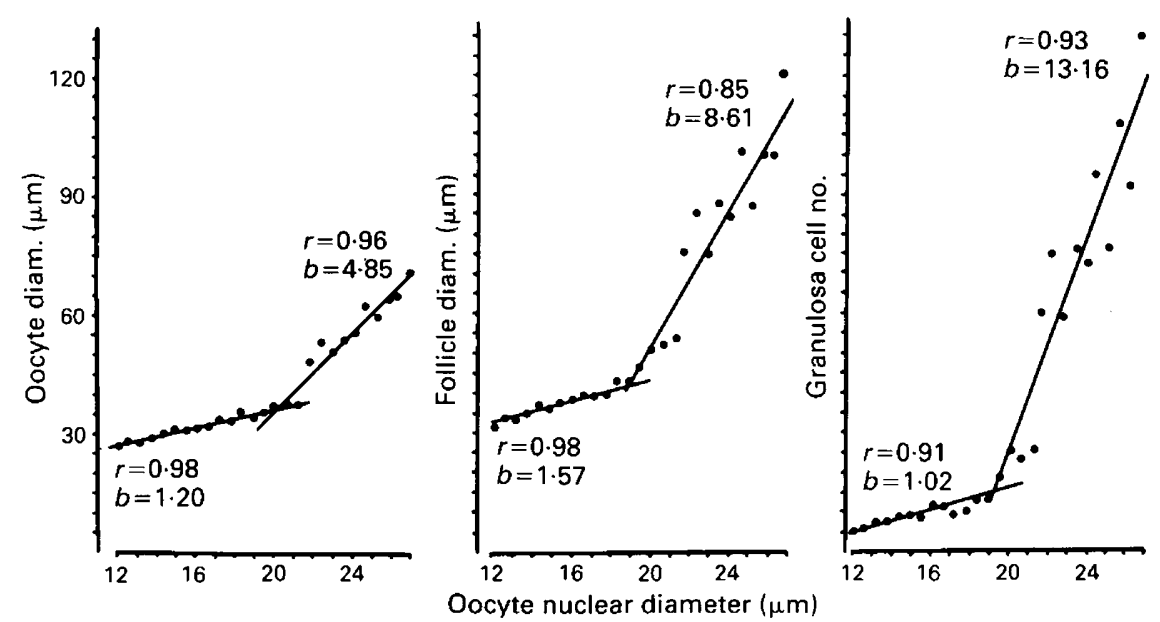

Fig. 3. Relationships between oocyte nuclear diameter with granulosa cell number in the largest cross section, oocyte diameter and follicle diameter of 1000 small ovarian follicles: $b=$ slope of the regression line $(y=a+b x)$.

largest cross-section, and oocyte nuclear diameter showed two distinct phases of follicular development (Fig. 3). During phase I (up to oocyte nuclear diameter of $19 \mu \mathrm{m}$ for follicular diameter and granulosa cell number and of $20 \mu \mathrm{m}$ for oocyte diameter) the 3 follicular measures showed little change. There were significant $(P<0.001)$ linear relationships and the slopes of the regression lines were similar, $1.20,1.57$ and 1.02 respectively. In phase II (which includes large Type C and all Type 
$\mathrm{D}$ follicles) there was a rapid increase in all the three measures, giving significant $(P<0.001)$ linear relationships but the slopes of the regression lines differed.

\section{Transformation of follicles of Type $B$ to $B / C$ and Type $B / C$ to $C$}

The kinetics of transformation of flattened to cuboidal granulosa cells in relation to the increase of granulosa cell number in the largest cross-section are shown in Fig. 4. Up to the 5-cell stage all the cells were flattened in their morphology. The first cuboidal cell appeared at the 5-cell stage. The percentage of cuboidal cells was low up to the 7-cell stage, after which there was a rapid fall in the percentage of flattened granulosa cells and, by the 20 -cell stage, a complete transformation to cuboidal cells was achieved.

Plots of the changes of percentages of follicles of Type B, B/C, C and D in relation to the increase of oocyte nuclear diameter (Fig. 5) revealed that the percentage of Type B follicles decreased rapidly and was very low when oocyte nuclear diameter was $>22 \mu \mathrm{m}$. A rapid formation of Type $\mathrm{D}$ follicle took place when oocyte nuclear diameter exceeded $18 \mu \mathrm{m}$.

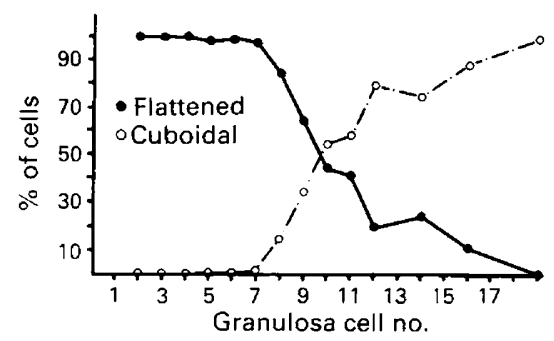

Fig. 4. Relationships between granulosa cell number in the largest cross-section and distribution pattern of flattened and cuboidal cells. Each point is the mean value of 15-20 follicles of 5 ovarian samples.

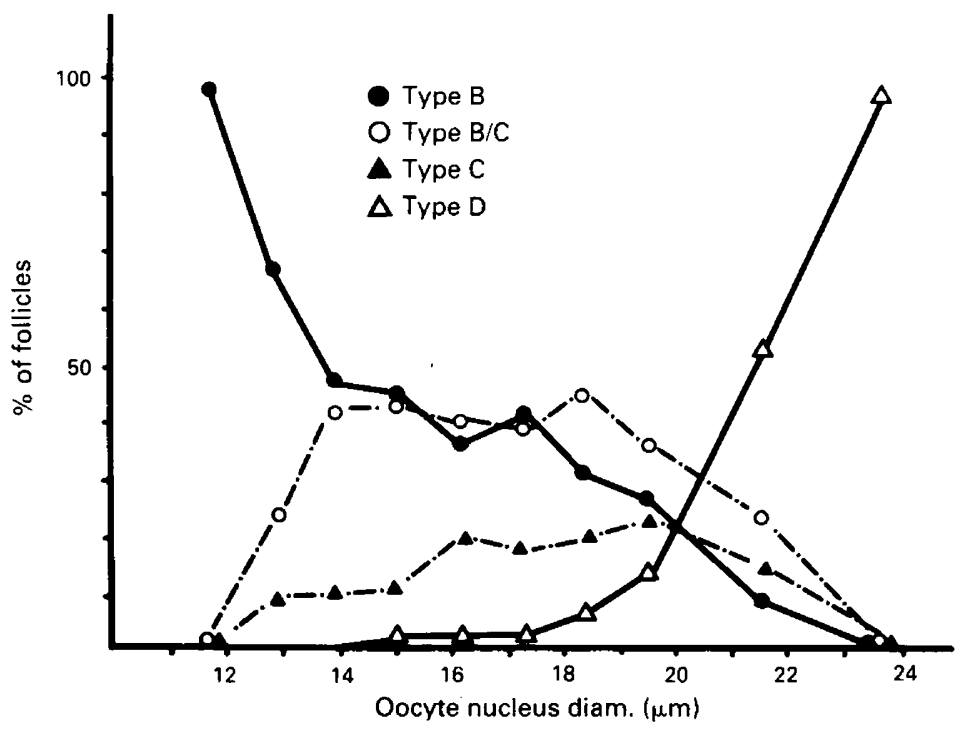

Fig. 5. Relationships between oocyte nuclear diameter and the distribution percentages of follicles of Types B, B/C, C and D. Data from 1000 follicles. 
The morphometric study of follicles of Types B, B/C and C showed that there was no significant difference in the mean diameters of their oocytes or of their germinal vesicles (Table 2).

\section{Effect of age on the development of each type of follicle}

When left and right ovaries could be distinguished $(n=25)$, there was no significant difference between the follicular populations of the two ovaries. With increasing age, the total ovarian follicular population and the numbers of each follicle type decreased significantly $(P<0.001$, Table 3). The percentages of Type $B$ follicles significantly decreased with the increasing age $(P<0.01)$ whereas percentages of follicles of Types B/C, C and D increased $(P<0.05,0.01$ and 0.05 respectively, Table 4 ). When the results were plotted as percentages of different follicular types versus $\log$ of the total ovarian follicular population a positive correlation was observed for follicles of Type $\mathrm{B}(n=80, r=0.60, P<0.001)$ and a negative correlation for those of Types C and D ( $n=80, r=0.61$ and $-0.54, P<0.001$, Fig. 6).

\section{Effect of the number of small follicles on the development of each type of follicles}

Among pairs of ovaries coming from 37 patients, 28 presented some differences in the total numbers of small follicles between ovulatory and contralateral ovary. To differentiate the respective effects of age and number of small follicles on the development of each type of follicles, the percentages of the different types of follicles have been compared. In these pairs of ovaries: (i)

Table 2. Morphometric characteristics of follicles of Types $B, B / C, C$ and $D$ and their percentage distribution in the total number of small follicles in the human ovary

\begin{tabular}{|c|c|c|c|c|c|c|}
\hline \multirow{2}{*}{$\begin{array}{l}\text { Type of } \\
\text { follicle }\end{array}$} & \multirow{2}{*}{$\begin{array}{l}\text { Follicular } \\
\text { diam. }(\mu \mathrm{m})\end{array}$} & \multirow{2}{*}{$\begin{array}{c}\text { Oocyte } \\
\operatorname{diam} .(\mu \mathrm{m})\end{array}$} & \multirow{2}{*}{$\begin{array}{l}\text { Oocyte nuclear } \\
\text { diam. }(\mu \mathrm{m})\end{array}$} & \multicolumn{2}{|c|}{ Granulosa cells } & \multirow{2}{*}{$\begin{array}{c}\% \text { of } \\
\text { population }\end{array}$} \\
\hline & & & & Mean no. & Range & \\
\hline B (408) & $35 \cdot 4 \pm 6 \cdot 2$ & $32 \cdot 1 \pm 6 \cdot 0$ & $16 \cdot 1 \pm 6 \cdot 1$ & $13 \pm$ & $7-23$ & $40 \cdot 8$ \\
\hline $\mathrm{B} / \mathrm{C}(409)$ & $37 \cdot 8 \pm 8 \cdot 2$ & $31 \cdot 7 \pm 8 \cdot 0$ & $16 \cdot 3 \pm 4 \cdot 0$ & $28 \pm$ & $9-50$ & $40 \cdot 9$ \\
\hline$C(153)$ & $46 \cdot 0 \pm 6 \cdot 2$ & $32 \cdot 6 \pm 4 \cdot 9$ & $16 \cdot 7 \pm 2 \cdot 5$ & $76 \pm 27$ & $23-223$ & $15 \cdot 3$ \\
\hline $\mathrm{D}(30)$ & $77 \cdot 2 \pm 10 \cdot 9$ & $47 \cdot 8 \pm 12 \cdot 0$ & $20 \cdot 9 \pm 3 \cdot 3$ & $360 \pm 185$ & $60-990$ & $3 \cdot 0$ \\
\hline
\end{tabular}

Data expressed as mean \pm s.d. for the no. of follicles given in parentheses.

Table 3. Total number $\left(\times 10^{-3}\right)$ of different types of small follicles from human ovaries in various age groups

\begin{tabular}{|c|c|c|c|c|c|c|}
\hline \multirow[b]{2}{*}{$\begin{array}{l}\text { Follicular } \\
\text { type }\end{array}$} & \multicolumn{5}{|c|}{ Age groups (years) } & \multirow[b]{2}{*}{$r$} \\
\hline & $\begin{array}{c}19-30 \\
(5)\end{array}$ & $\begin{array}{c}31-35 \\
(9)\end{array}$ & $\begin{array}{c}36-40 \\
(13)\end{array}$ & $\begin{array}{c}41-45 \\
(28)\end{array}$ & $\begin{array}{l}\geq 46 \\
(26)\end{array}$ & \\
\hline B & $51.9 \pm 9.0$ & $19 \cdot 5 \pm 2 \cdot 8$ & $9 \cdot 7 \pm 1 \cdot 1$ & $4.9 \pm 1.5$ & $1 \cdot 3 \pm 0.2$ & $-0.87^{*}$ \\
\hline $\mathrm{B} / \mathrm{C}$ & $21.8 \pm 2.7$ & $10.6 \pm 1.7$ & $6 \cdot 0 \pm 1 \cdot 3$ & $3.1 \pm 0.7$ & $0.9 \pm 0.1$ & $-0.85^{*}$ \\
\hline $\mathrm{C}$ & $4.9 \pm 0.6$ & $2 \cdot 3 \pm 0 \cdot 3$ & $1 \cdot 5 \pm 0.4$ & $0.7 \pm 0.1$ & $0.3 \pm 0 \cdot 1$ & $-0 \cdot 86^{*}$ \\
\hline D & $1.0 \pm 0.1$ & $0.9 \pm 0.2$ & $0.3 \pm 0.1$ & $0.1 \pm 0.1$ & $0.1 \pm 0.1$ & $-0.82^{*}$ \\
\hline Total & $79.6 \pm 12.4$ & $33 \cdot 3 \pm 4 \cdot 0$ & $20 \cdot 6 \pm 3 \cdot 7$ & $8.9 \pm 2 \cdot 1$ & $2 \cdot 7 \pm 0.4$ & $-0 \cdot 70^{*}$ \\
\hline
\end{tabular}

Values are mean \pm s.e.m. for the no. of ovaries in parentheses.

$* P<0.001$. 

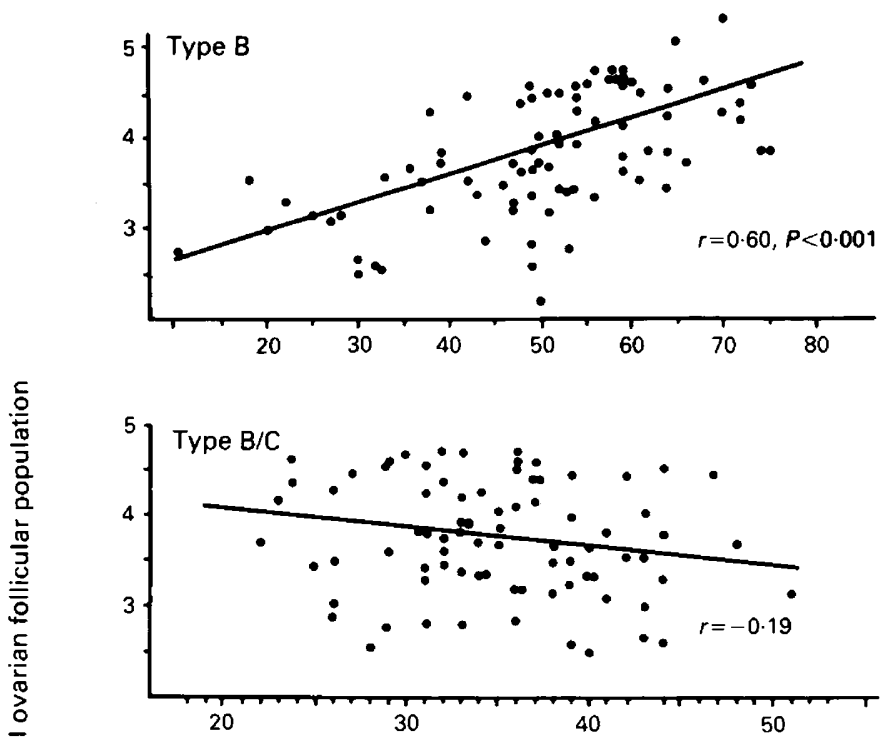

$+$

Type C

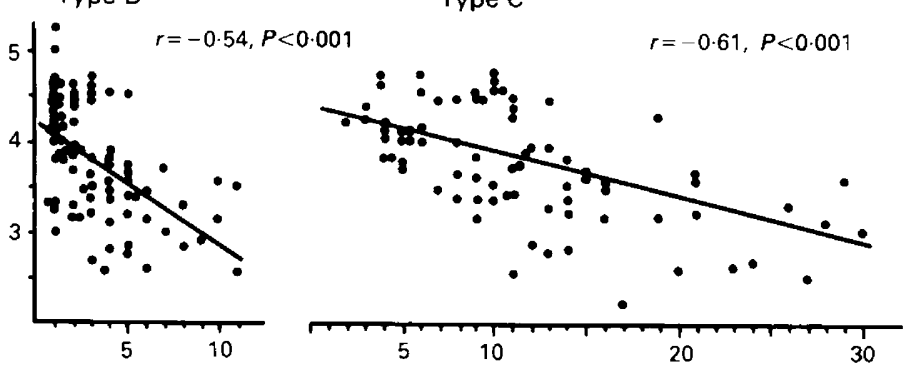

Percentage of follicles

Fig. 6. Relationships between proportions of follicles of Types B, B/C, C and D with $\log$ of the total follicular population in 86 ovarian samples.

Table 4. Percentages of different types of small follicles from human ovarian samples in various age groups

\begin{tabular}{|c|c|c|c|c|c|c|}
\hline \multirow[b]{2}{*}{$\begin{array}{l}\text { Follicular } \\
\text { type }\end{array}$} & \multicolumn{5}{|c|}{ Age group (years) } & \multirow[b]{2}{*}{$r$} \\
\hline & $\begin{array}{c}19-30 \\
(6)\end{array}$ & $\begin{array}{c}31-35 \\
(10)\end{array}$ & $\begin{array}{c}36-40 \\
(13)\end{array}$ & $\begin{array}{c}41-45 \\
(31)\end{array}$ & $\begin{array}{l}\geq 46 \\
(26)\end{array}$ & \\
\hline B & $62 \cdot 2 \pm 1.9$ & $57.8 \pm 3.6$ & $54 \cdot 5 \pm 3 \cdot 0$ & $49 \cdot 5 \pm 1.9$ & $45 \cdot 1 \pm 3 \cdot 2$ & $-0.44 \dagger$ \\
\hline $\mathrm{B} / \mathrm{C}$ & $29 \cdot 7 \pm 1 \cdot 7$ & $30 \cdot 9 \pm 2 \cdot 6$ & $35 \cdot 4 \pm 2 \cdot 0$ & $36 \cdot 3 \pm 1 \cdot 0$ & $35 \cdot 0 \pm 1 \cdot 5$ & $0 \cdot 29^{*}$ \\
\hline $\mathrm{C}$ & $6.0 \pm 1.4$ & $7 \cdot 5 \pm 1.5$ & $7 \cdot 9 \pm 1 \cdot 1$ & $11 \cdot 3 \pm 1 \cdot 2$ & $15 \cdot 3 \pm 2 \cdot 0$ & $0.40^{\dagger}$ \\
\hline D & $1.7 \pm 0.3$ & $4 \cdot 1 \pm 1 \cdot 2$ & $2 \cdot 2 \pm 0.4$ & $2.9 \pm 0.4$ & $4.5 \pm 0.6$ & $0 \cdot 24^{*}$ \\
\hline
\end{tabular}

Values are mean \pm s.e.m. for the no. of ovaries in parentheses.

$* P<0.05 ;+P<0.01$. 
the percentages of Type B follicles were significantly lower $(P<0.02$, paired $t$ test) and (ii) the percentages of Type $C$ follicles were significantly greater $(P<0.02$, paired $t$ test $)$ in the ovaries showing the lowest number of small follicles than in the contralateral ovary.

\section{Discussion}

The changes of the diameters of the follicle and its oocyte and of the number of granulosa cells in the largest cross-section in relation to the oocyte nuclear diameter show that the development of small follicles can be divided into two distinct phases. The first phase, corresponding to transformation of granulosa cells from flattened to cuboidal shape with no appreciable increase in number can be called the dormant phase. During this phase, except for very small oocytes only observed in Type B follicles, the range of the oocyte nuclear diameters is similar for follicles of Types $\mathrm{B}, \mathrm{B} / \mathrm{C}$ and $\mathrm{C}$. This suggests that, during the dormant phase, Type $\mathrm{B}$ follicles change into Type $B / C$ then into small Type $C$ follicles with no major increase in the oocyte and follicular diameters and in number of granulosa cells in the largest cross-section. The second phase during which the size of oocyte and follicle and number of granulosa cells increase with the increase of oocyte nuclear diameter is the growth phase.

The growth rate of the oocyte is slower than that of the follicle which is, in turn, slower than that of the granulosa cell number. The starting point of this phase has been chosen as the intersection point of the two regression lines and can be considered as the initiation of follicular growth. This phase starts when the oocyte nucleus, oocyte and follicle diameters reach 19-20,36 and $43 \mu \mathrm{m}$ respectively and when there are about 15 granulosa cells in the largest cross-section. This is in good agreement with the results obtained for the mouse (Lintern-Moore \& Moore, 1979; Moore \& Lintern-Moore, 1979) and for the sheep (Cahill \& Mauléon, 1981). In the mouse, growth of follicles starts when there are 10 cells in the largest cross-section which also reflects a simultaneous increase in RNA polymerase activity. In sheep the critical point is 14 cells (Cahill \& Mauléon, 1981). Nevertheless, there does not seem to exist, in the human, a growth phase with a reduced speed as described for sheep by Cahill \& Mauléon (1981). The increase in the size of oocyte nuclear diameter is associated with a simultaneous increase in the number of Type $\mathrm{D}$ follicles and decrease in numbers of Type $\mathrm{B}, \mathrm{B} / \mathrm{C}$ and $\mathrm{C}$ follicles.

The process which regulates the initiation of follicular growth is not clear. A role of gonadotrophins in this initiation is ruled out since neither exogenous gonadotrophin treatment (Peters et al., 1973b) nor neutralization of internal gonadotrophins by their respective antisera (Eshkol et al., 1970) alters the number of follicles in the ovary that start to grow. The possibility that the ovary itself may regulate the process of initiation of follicular growth cannot be ruled out because the decrease of the size of non-growing pool of follicles by treatment with 9:10-dimethyl1:2-benz-anthracene (Krarup et al., 1969) or by testosterone treatment (Peters et al., 1970) resulted in a simultaneous reduction in the number of follicles that start to grow. This is in agreement with the above hypothesis. However, conversion of the data of Peters et al. (1970) to percentages reveals an increase in the percentage of growing follicles in testosterone-treated animals in which the pool size of small follicles decreases in comparison to control animals.

The observed decrease of the total pool with the increasing age is in good agreement with the results of Block (1952). However, if the numbers of all the types of small follicles also decreased with increasing age, their proportions expressed as percentages of the total follicular population did not change in the same way. With the increase in age, the percentages of Type $B$ follicles decreases whereas the percentages of Types $C$ and $D$ increased. This could be due to a progressive transformation with age of Type B follicles into Type B/C then into Type $C$ follicles. Such a process seems to be confirmed by the changes of the percentages of different types of small follicles by age group. It was noticed that the percentages of Type B follicles decreased regularly whereas those of Type B/C did not increase after the age of 35 years and those of Type $C$ increased markedly after the age of 
40 years. These differences could reflect the normal changes affecting small follicles during the dormant phase. Nevertheless, when these percentages were compared with the total follicular population there were positive correlations for Type B follicles and negative correlations for follicles of Types $\mathrm{C}$ and $\mathrm{D}$.

The smaller the total ovarian follicular population, the smaller was the percentage of Type B follicles and the greater the percentage of Type $C$ follicles. Such an increase in the percentage of Type $\mathrm{C}$ follicles could be an adaptive process, allowing the ovary to promote the growth of a sufficient number of follicles to permit one of them to achieve its complete development and ovulate, despite the reduction in the number of available follicles. Because the total ovarian follicular population decreases significantly with age, the adaptive process may be related to age and can be considered as an extra-ovarian regulator or to the total ovarian follicular population, i.e. intra-ovarian regulation.

The observations of the percentages of the different types of follicles in the two ovaries of the same patient showed that the changes in the percentages of follicles of Types B and C are not very dependent on the age factor and are especially related to the size of the total follicular population.

In the human ovary, therefore, an intraovarian mechanism may be operating to regulate the initiation of follicular growth, and perhaps to maintain a sufficient number of follicles necessary for further follicular development. It is possible that follicles of Types $\mathrm{B}$ and $\mathrm{B} / \mathrm{C}$ may exert some inhibitory influence on the initiation of Type $\mathrm{C}$ follicle growth. This inhibitory influence could be directly proportional to the size of the pool of small follicles. Nevertheless, it has been suggested that degenerating follicles contain a substance which reduces the initiation of the follicular growth (Peters et al., 1973a). As a strict correlation exists between the pool of small follicles and the population of large growing follicles in women (Gougeon, 1984), it could be postulated that, with increasing age and decreasing population of large atretic follicles, the secretion of an inhibitory substance coming from these follicles could decrease and, consequently, promote the initiation of growth of follicles of Type C.

Further investigations using experimental reduction of the pool of small follicles in young primates could give an answer to the nature of this adaptive process.

G.B.N.C. is indebted to the Government of France for a fellowship to carry out this research project. We thank Professor E. Martin, Dr H. Mazabraud, Professor E. Papiernik and Dr M. Prade for providing clinical samples; Françoise Nomé for excellent technical assistance; and Dr R. Forman for help with the English translation.

\section{References}

Block, E. (1951a) Quantitative morphological investigations of the follicular system in women; methods of quantitative determinations. Acta anat. 12, 267-285.

Block, E. (1951b) Quantitative morphological investigations of the follicular system in women; variations in the different phases of the sexual cycle. Acta endocr., Copenh. 8, 33-54.

Block, E. (1952) Quantitative morphological investigations of the follicular system in women; variations at different ages. Acta anat. 14 (Suppl. 16), 108-123.

Cahill, L.P. \& Mauléon, P. (1981) A study of the population of primordial and small follicles in the sheep. $J$. Reprod. Fert. 61, 201-206.

Eshkol, A., Lunenfeld, B. \& Peters, H. (1970) Ovarian development in infant mice. Dependence on gonadotrophic hormones. In Gonadotrophins and Ovarian Development, pp. 249-258. Eds W. R. Burt, A. C. Crook \& M. Ryle. Livingstone, London.
Gougeon, A. (1984) Caractères qualitatifs et quantitatifs de la population folliculaire dans l'ovaire humain adulte. Contr. Fert. Sexual. 12, 527-535.

Gougeon, A. \& Lefèvre, B. (1984) Histological evidence of alternating ovulation in women. $J$. Reprod. Fert. 70, 7-13.

Koering, M.J. (1983) Preantral follicle development during the menstrual cycle in Macaca mulatta ovary. J. Anat. 166, 429-443.

Krarup, T., Pedersen, T. \& Faber, M. (1969) Regulation of oocyte growth in the mouse ovary. Nature, Lond. 224, 187-188.

Lintern-Moore, S. \& Moore, G.P.M. (1979) The initiation of oocyte growth in the mouse ovary. Annls Biol. anim. Biochim. Biophys. 19, 1399-1407.

Lintern-Moore, S., Peters, H., Moore, G.P.M. \& Faber, M. (1974) Follicular development in the infant human ovary. J. Reprod. Fert. 39, 53-64. 
Moore, G.P.M. \& Lintern-Moore, S. (1979) Patterns of gene activity during ovum formation in the mouse. Annls Biol. anim. Biochim. biophys. 19, 1409-1417.

Peters, H., Sörensen, I.N., Byskov, A.G., Pedersen, T. \& Krarup, T. (1970) The development of the mouse ovary after testosterone propionate injection on day 5. In Gonadotrophins and Ovarian Development, pp. 351-361. Eds W. R. Burt, A. C. Crook \& M. Ryle. Livingstone, London.
Peters, H., Byskov, A.G. \& Faber, M. (1973a) Intraovarian regulation of follicle growth in the immature mouse. In The Development and Maturation of the Ovary and its Function, pp. 20-23. Ed. H. Peters. Excerpta Medica, Amsterdam.

Peters, H., Byskov, A.G., Lintern-Moore, S., Faber, M. \& Andersen, M. (1973b) The effect of gonadotropins on follicular growth initiation in neonatal mouse ovary. J. Reprod. Fert. 35, 139-141.

Received 9 March 1987 